RESEÑAS

\title{
Una mirada al trabajo doméstico no asalariado y su vinculación con la producción capitalista
}

\author{
Constanza Acevedo Oyarce (iD \\ Universidad de Chile
}

9 Federici, Silvia. El patriarcado del salario: Críticas feministas al marxismo. Buenos Aires: Tinta Limón, 2018, 128 páginas.

Lo que llaman amor, nosotras lo llamamos trabajo no pagado.

Silvia Federici

En la dinámica de relaciones que vislumbramos dentro de la sociedad, ha existido de forma permanente una lógica primaria de clasificación del trabajo en torno al género, a partir de la cual a las mujeres se les han asignado ciertas tareas de carácter reproductivo, mientras que a los hombres se les ha asociado con el área laboral ajena a las labores del hogar, es decir, con el ejercicio público del trabajo, que es, por tanto, asalariado.

Dentro de este contexto, este libro nace de una serie de ensayos con perspectiva crítica escritos por la autora, en los cuales presenta una tesis bastante clara en torno al trabajo doméstico. Dicha tesis se expresa o se puede entender de la siguiente forma: «El trabajo doméstico no es un trabajo precapitalista o un trabajo natural, sino que más bien es un trabajo que ha sido conformado para el capital por el capital, es decir, es absolutamente funcional a la organización del trabajo capitalista», a través de creaciones como la figura del ama de casa a tiempo completo. Junto con aquello, la autora plantea una crítica al marxismo, pues éste no da cuenta del proceso de reforma del trabajo que estaba teniendo lugar, el cual significó una modelación de la fuerza de trabajo a los intereses del capital.

Por lo tanto, el presente texto no sólo estudia el trabajo doméstico no asalariado y sus implicancias, sino que es una crítica a todo el trabajo teórico que se ha publicado en torno al modelamiento del trabajo y el capital. 
Dado ello, el presente libro se plantea como una invitación a mirar de forma crítica el modelo actual de división laboral, no sólo en lo que respecta al trabajo doméstico y al no asalariado que han llevado a cabo por regla general las mujeres en la historia más reciente, sino que también encontraremos un acercamiento a cómo el capital ha moldeado las fuerzas de trabajo a fin de mantener el control sobre los aspectos más íntimos de los sujetos.

A partir de lo anterior, podemos decir que, para el capital, un avance significativo en el control de la fuerza de trabajo fue la reforma ocurrida a finales del siglo XIX, debido a que tuvo como pilar fundamental rechazar el trabajo de las mujeres dentro de las fábricas y aumentar progresivamente el salario de los hombres bajo la denominación de «salario familiar», lo cual tenía como fin que las primeras se dedicasen primordialmente a las labores de reproducción y lo hombres a las de producción; de este modo se creó la figura del ama de casa a tiempo completo.

Dicha reforma en la práctica significó una modelación del trabajo por parte del capital, toda vez que las mujeres pasaron a sustentar parte importante de los objetivos del capitalismo en cuanto a producción, ya que aportaron significativamente a que los trabajadores acudiesen a las fábricas con menores preocupaciones, debido a que las mujeres se dedicaban no sólo a la mantención del hogar común, sino que también al cuidado de los hijos y la satisfacción sexual de los trabajadores. Es decir, el trabajo llevado a cabo por las mujeres desde sus hogares ha significado en la práctica «dejar a los trabajadores listos para que sean parte de la producción», en los términos que al capital le son útiles.

Ante esta reforma, la autora plantea que Marx no dio cuenta, en su trabajo, de la explotación que subyace al trabajo doméstico no asalariado que se llevaba a cabo por las mujeres y, junto con ello, tampoco logra vislumbrar la ya referida reforma estructural que se estaba forjando dentro del capitalismo, la cual trae aparejada una serie de consecuencias que repercuten hasta hoy. Un ejemplo de ello son las lógicas de poder que encontramos en el núcleo familiar, debido a que la falta de salario para el trabajo doméstico ha derivado en una fuerte asimetría de poder dentro del hogar, ya que las mujeres se han visto en una posición de sujeción para con el hombre, toda vez que su subsistencia ha pasado a depender de él. Dicha asimetría de poder se ha traducido en una violencia latente hacia la mujer que se vive no sólo en el espacio del hogar, sino que también en la sociedad misma.

Sumado a aquello, la autora señala que el control que ha significado esta reforma se ha expresado en la vida de las mujeres en la forma de control estatal ejercido sobre sus cuerpos, a través de una gran cantidad de prohibiciones que se han levantado a lo largo de los años en torno a la natalidad. Un ejemplo paradigmático en nuestro país es la legislación del aborto, pues recientemente se ha legislado la interrupción voluntaria del embarazo en tres causales acotadas que no logran abarcar el gran espectro de situaciones que vive una mujer ante un embarazo no deseado. 
Por lo tanto, el hecho de que las mujeres se queden trabajando desde sus casas y que se haya instalado con tanta fuerza la institución de la familia ha sido una «creación del capital para el capital, debido a que dicha institución ha sido clave al momento de garantizar la calidad y cantidad de la fuerza de trabajo, así como también para mantener el control sobre esta». La familia, por lo tanto, ha pasado a ser la institucionalización de nuestro trabajo no remunerado, de la dependencia salarial de las mujeres para con los hombres y, de la mano con aquello, ha pasado a ser un espacio de desigual división del poder, que ha significado un sinnúmero de violencias que se expresan tanto en el mundo familiar como en el ámbito más bien público.

A partir de ello, la autora establece que el no reconocer el trabajo que llevan a cabo las mujeres dentro de los hogares es «estar ciego ante el trabajo que realiza una abrumadora parte de la población mundial que se encuentra no asalariada». Junto con ello, es no reconocer el aporte significativo que ha hecho el trabajo doméstico y el resto de los trabajos no asalariados a la acumulación de capital, los cuales se han llevado a cabo desde los campos hasta las cocinas de nuestras casas, en forma muchas veces anónima.

Ahora, en cuanto a la referencia que hace la autora a que Marx no dio cuenta del trabajo doméstico, es relevante comenzar diciendo que, si bien su obra es clave en cuanto al aporte que ha significado en materia de análisis del capital y la clase, es fundamentalmente una obra escrita desde el punto de vista masculino. Es decir, Marx no teorizó sobre el género y, por tanto, se encuentra la explotación vivida por las mujeres como secundaria dentro de su obra: «Naturalizó el trabajo doméstico e idealizó el trabajo realizado en las industrias como la única forma de producción social y como el único potencial instrumento de nivelación de la desigualdad social». De la mano con lo anterior, la autora menciona que Marx en ningún momento de su libro El capital reconoce que «la reproducción de la fuerza de trabajo implica el trabajo no asalariado de las mujeres», sino que, al contrario, insiste en representar al «trabajador como un ente que se autorreproduce», invisibilizando así todo el trabajo que se produce dentro de los hogares y su fuerza revolucionaria.

Debido a ello, se evidencia en el presente libro que, a pesar de su gran aporte, existe un límite a la obra de Karl Marx. Aquel límite hace necesario repensar ese momento de la historia y los siguientes desde una perspectiva de género, en la que el punto de partida sean las cocinas y los dormitorios, un trabajo necesario desde el feminismo para no sólo superar aquel límite teórico, sino llevar adelante la demanda sobre el salario para el trabajo doméstico.

En conclusión, este libro aparece como un aporte significativo desde diversos puntos de vista. En primer lugar, aparece como relevante la reconstrucción histórica que hace sobre el inicio del trabajo doméstico y el ama de casa a tiempo completo como creación del capital para su propio beneficio, lo cual va de la mano con la instauración de la institución de la familia, que en su faceta tradicional ha significado 
estancamiento en el desarrollo individual de los sujetos. En segundo lugar, este libro aparece como una crítica certera a las categorías establecidas por Marx, que han invisibilizado el trabajo de reproducción llevado a cabo por las mujeres, llegando incluso a quedar su explotación como una preocupación de segunda categoría. Por tanto, aparece como necesario superar los límites teóricos de Marx, con el fin de reconocer el trabajo doméstico como una creación del capital que ha modificado con fuerza las relaciones interpersonales entre los sujetos y que, junto con ello, ha significado un avance para el capital en cuanto a modelación de la fuerza de trabajo.

Por último, podemos encontrar una abierta invitación de la autora a sobrepasar las divisiones y categorías entregadas por el capital, con el fin de avanzar en la creación de una sociedad nueva. Aquella invitación aparece como sumamente atingente al momento que vive el Chile del año 2020 , en que nos encontramos ad portas de vivir un proceso constituyente, que nos invita a reflexionar sobre temáticas tan relevantes como la institución de la familia, la libertad de decidir sobre el cuerpo propio y, porque no, el reconocimiento del trabajo doméstico como tal y la implementación de un salario para este.

\section{Referencias}

ARRIAGADA, Irma (2002). «Cambios y desigualdad en las familias latinoamericanas». Revista de la Cepal, 77: 143-161.

Fries, Lorena y Nicole Lacrampette (2013). «Feminismos, género y derecho». En N. Lacrampette (editora), Derechos humanos y mujeres: Teoría y Práctica (pp. 33-68). Santiago: Centro de Derechos Humanos.

RodríGUEZ, Blanca (2011). «Matrimonio, género y familia en la constitución española: Trascendiendo la familia nuclear». Revista Española de Derecho Constitucional, 91: 69-10.

\section{Sobre la autora}

Constanza Acevedo Oyarce es estudiante de Derecho en la Universidad de Chile. Actualmente se desempeña como ayudante ad honorem en el Centro de Derechos Humanos y en el Departamento de Derecho Procesal de la misma universidad. Su correo electrónico es constanza.acevedo@derecho.uchile.cl. (D) https://orcid. org/0000-0001-6021-7410. 
El Anuario de Derechos Humanos es una publicación semestral de referencia y consulta en materia de derechos humanos y campos afines. Busca ser un espacio de discusión de los temas centrales en el ámbito nacional e internacional sobre derechos humanos. Es publicado desde 2005 por el Centro de Derechos Humanos de la Facultad de Derecho de la Universidad de Chile.

\author{
EDITORA \\ Claudia Iriarte Rivas \\ ciriarter@derecho.uchile.cl \\ SITIO WEB \\ anuariocdh.uchile.cl \\ CORREO ELECTRÓNICO \\ anuario-cdh@derecho.uchile.cl \\ LICENCIA DE ESTE ARTÍCULO \\ Creative Commons Atribución Compartir Igual 4.o Internacional
}

\author{
\% \\ La edición de textos, el diseño editorial \\ y la conversión a formatos electrónicos de este artículo \\ estuvieron a cargo de Tipográfica \\ (www.tipografica.io)
}

